流犰の可視化 Vol. 4 No. 14 (1984 年 7 月)

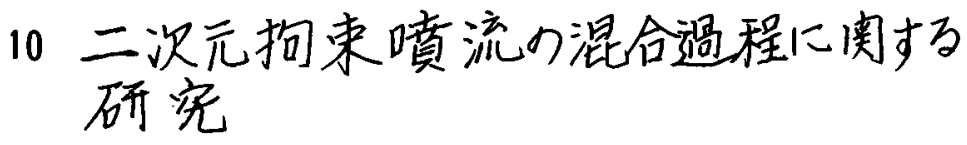

\title{
東海大工 青木克已。，大田紘昭，中山泰喜。
}

\author{
Study on Mixing Process of Two-dimensional \\ Confined Jet
}

Katsumi AOKI, Hiroaki OHTA, Yasuki NAKAYAMA

\begin{abstract}
This paper is study on mixing process of twodimensional confined jet. Confined jet flow is very important for combustion chamber, jet pump, fluidic device, etc.

In this study, flow pattern of mixing chamber has been investigated by using flow visualization technics.

As a result, it has made clear the separation point, reattachment point and separation region for effect of Reynolds number and velocity ratio.
\end{abstract}

\section{1. 緒言}

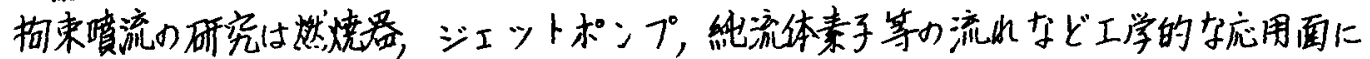

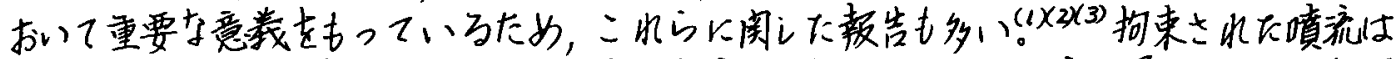
混合管の壁面ではく離を生じる太め不安定な流水上子る。こ水らの流水埸にプローブを样

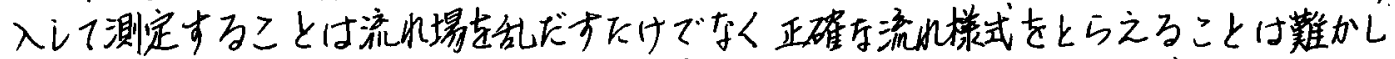

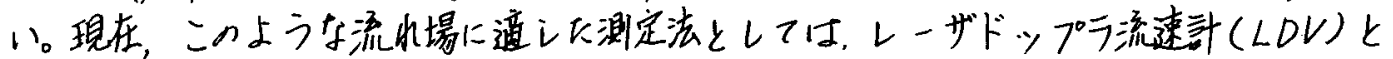
流化の可視化であろう。前者のLDVK詨し復者の可視化は单一時间以测定断面上の流水埸 を一㥞以把握できるニとである。

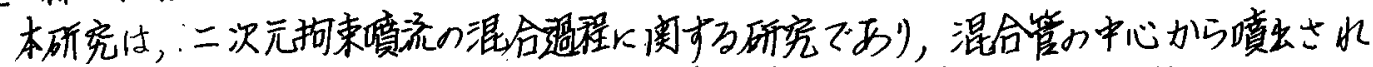

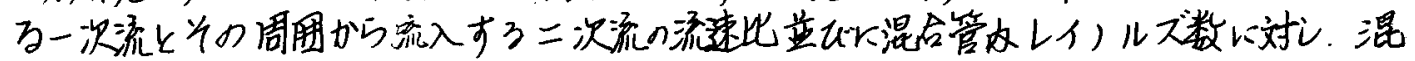

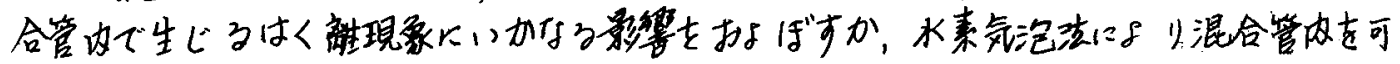
視化明的かに方いる。

Faculty of Engineering, Tokai University, Hiratsuka, Kanagawa. 
2. 訊号

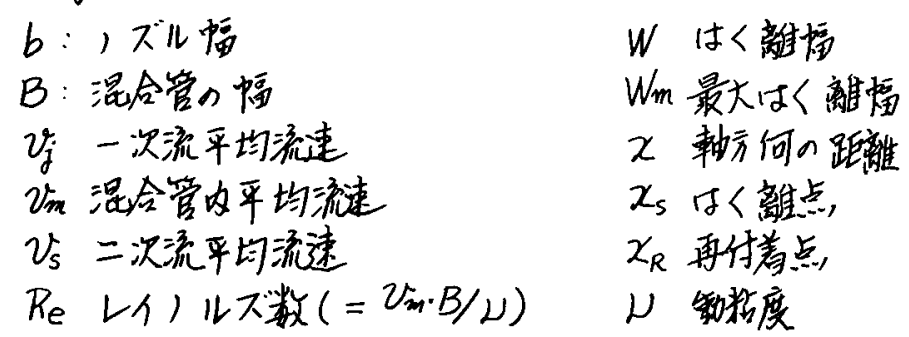

3. 实联装置和代方法

Fig 1 は二次元抲束喷流实汫 装置概略で历方。装置本体格明 ナアクリル慗で，，ズル幅b=15 $m m$ ，混合管の幅 $B=60$ mmであ る.水位は $80 \mathrm{~mm}$ でエり底か560 mma位置に水素気泡法で可視化

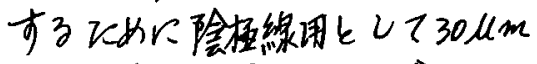

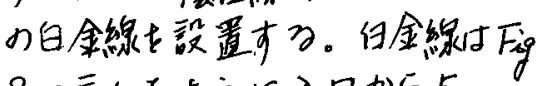
2 に示したように入口か5 $5 \mathrm{~mm}$ の位㯰を基点に川本設定した。通 常陽琶柾は流路の下流以設けつ加

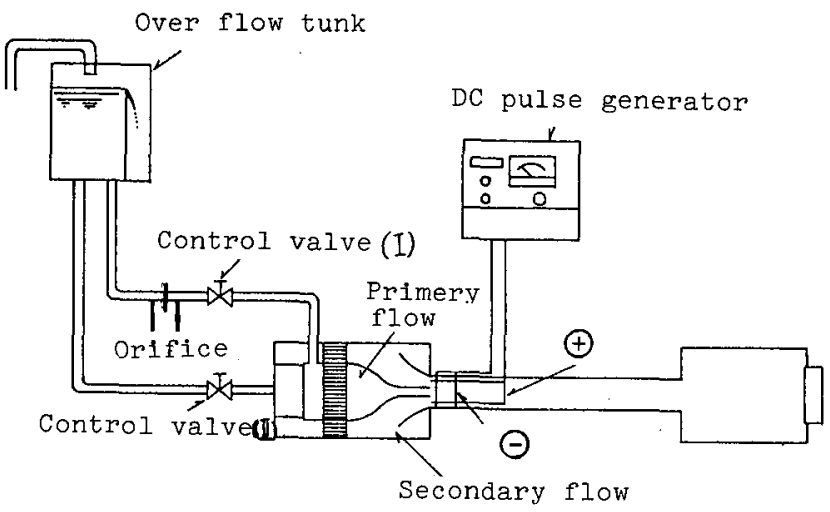
本实㧎のように複数的险柾絈より タンデムに水素気泡を発生えせる 火各白金综㛠的電位差により水素

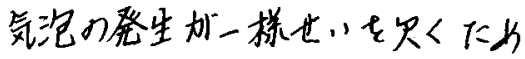
水路底方左右の角に混合管入口よ り可視化領域の全長にわに少銅線 Fig.l Experimental apparatus

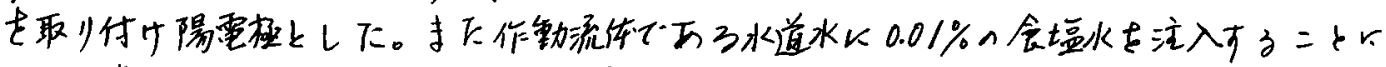

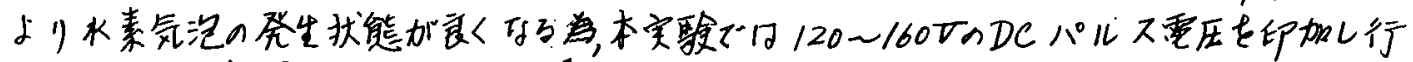

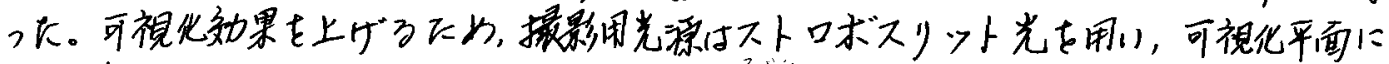

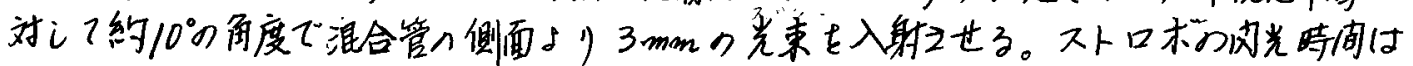

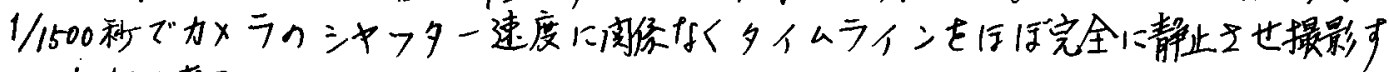
ろこと加できる。

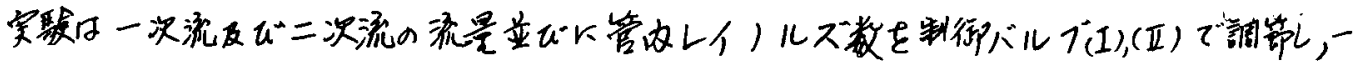

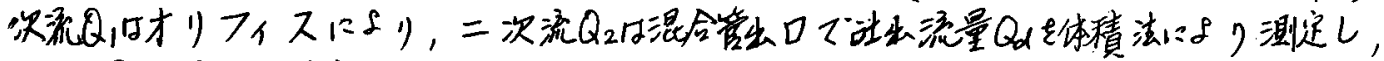
$Q_{2}=Q_{d}-Q_{1}$ より決定する.

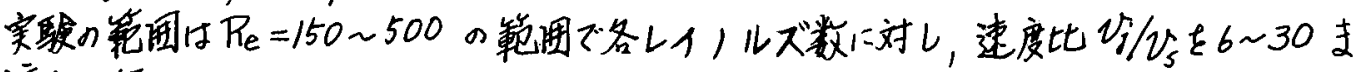
で变之て行った。 
4. 結果及代考察 Fig3は管内レイ

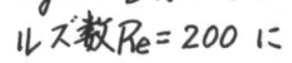
对し，速度比 $V_{s} / v_{s}$ を $8,14,18,30$ と变 えた時の流れの一 例を示している。

この流れはタイ ムラインにより可 視化したもので， 二小可視化写真よ 混合管内血速度 分布の变化火混合 管壁面近傍で道 流点、はく離点, はく離厚き，再付 着点热どの流勳模

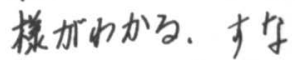
小5、はく㒕現象 は速度比が大きく 少るとつ水影著に

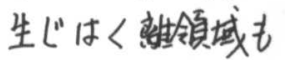
增していることが わかる。

Fig 4 は可視化 军真加的逆流点( 流速加ゼ口の点) を結儿て形成之れ 门辟面との領域か はく噰領域である。 速度比加大きく 热るに従がいはく 新点比上流へを移 動しはく離领域を 增亏倾向加見られる

Fig 5 は速度比の 变化に対するはく離

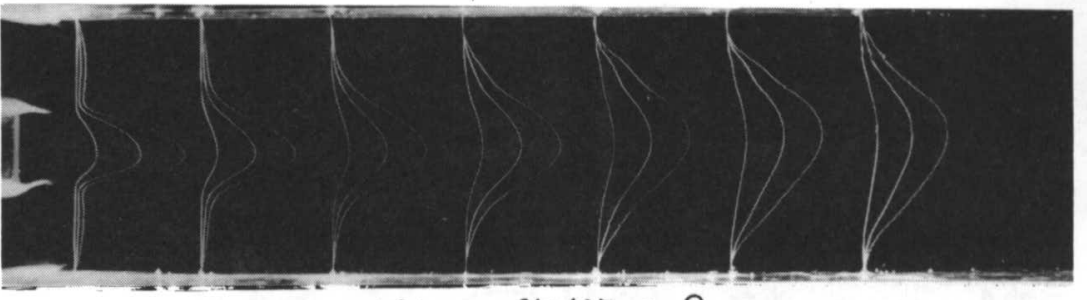

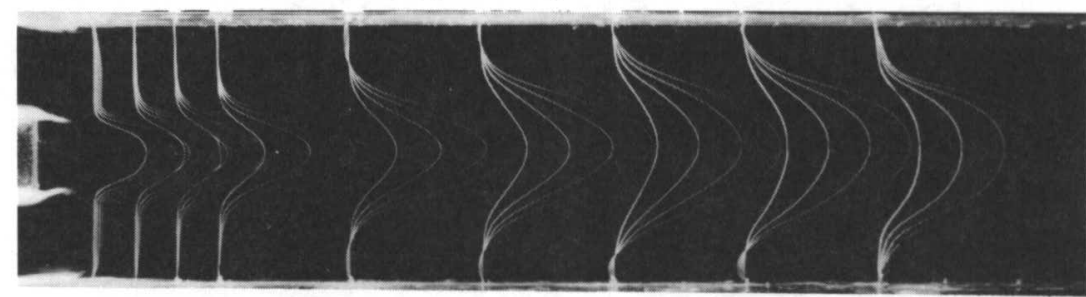

(b) $\quad v_{j} / v_{s}=14$

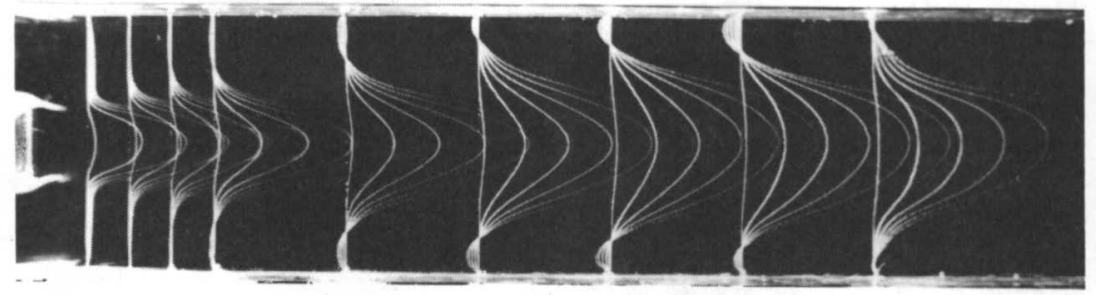

(C) $\quad v_{j} / v_{s}=18$

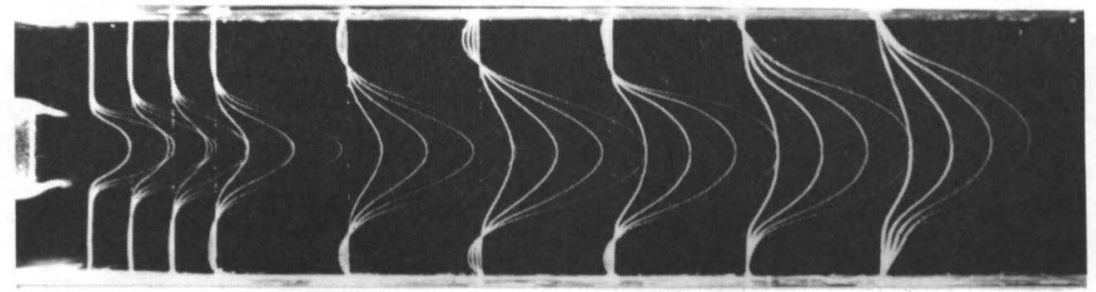

(d) $\quad v_{j} / V_{s}=30$

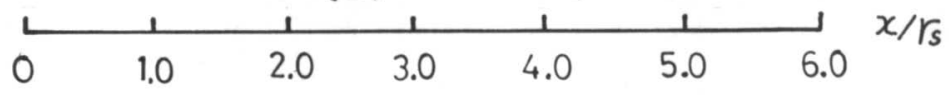

Fig. 3 Flow pattern of mixing chamber by hydrogen bubble method

$[R e=200, P . W=15 \mathrm{~ms}, P . I=0.5 \mathrm{~s}, F=5.6$, Strobo slite light]

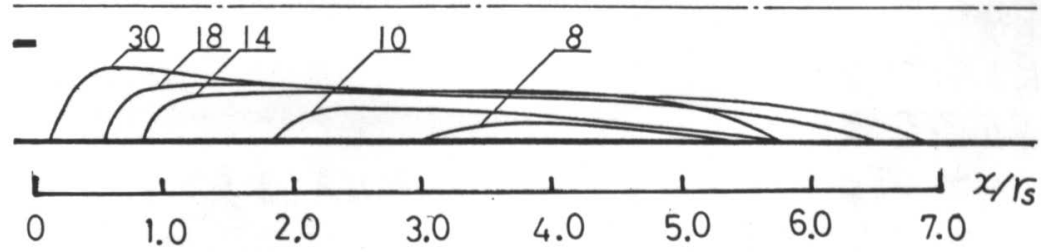

Fig. 4 Separation region 
点，はく離領城の大きそ， 再付着点の闵俰を示して いる。速度比加大 $2<\tau_{\delta}$ るに徒が、はく維点の上 流入移し二次流入口近仍 ら始まうている。ま飞， はく赫領城も塔し，最大 はく端度之も二次流入口 近くぐ生ヒているンとが のかる、最大はく離原之 はレイルズ数が新。

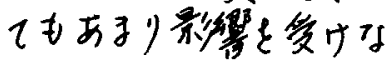

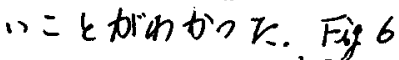
はレイ）儿ス数上速度比

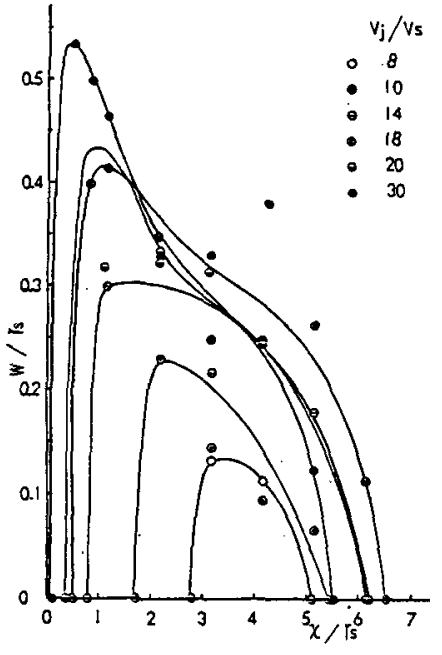

Fig. 5 Separation region for velocity ratio の要化に対する最大はく

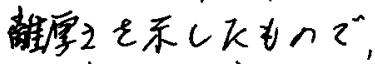
はく離原之加速度比的子 以由保し，速度比加增万反 はく新原之加增している。

Fig7ウレイノルズ数と 速度比の变化火祄するは く踓点の位置を示している。 レイルズ数が增すとはく

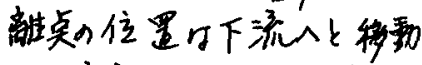
し、速度比加小きい程、日 く新位置的差は大き《小 ろ比向向示している。

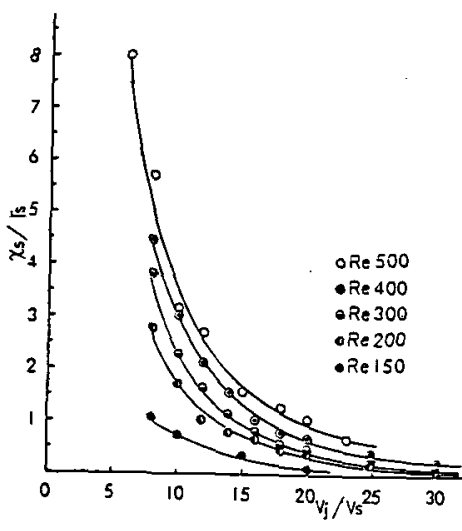

F1g.7 Separation point for Reynolds number

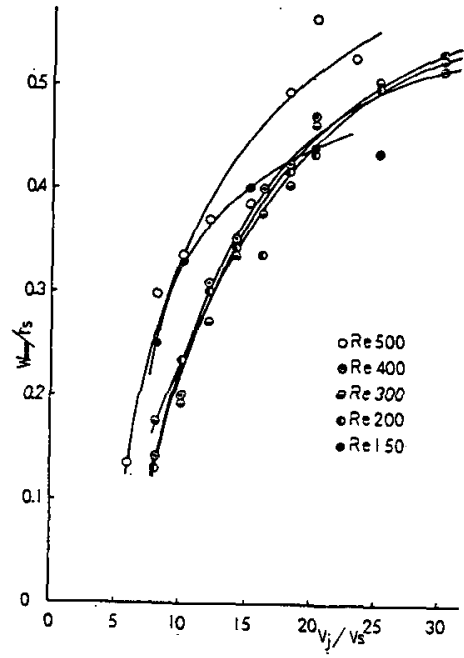

Fig. 6 Maximum thickness of separation

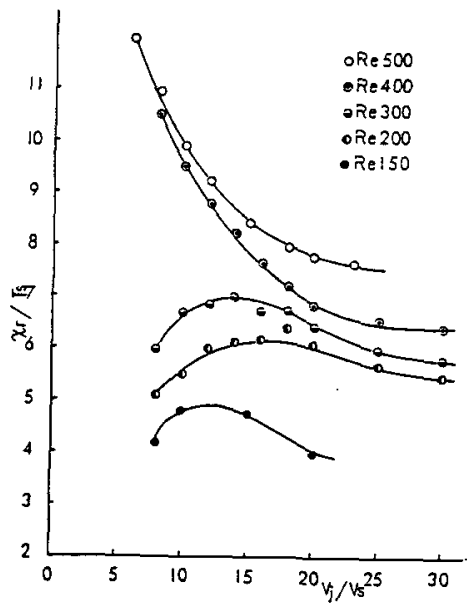

Fig. 8 Reattachment point for Reynolds number

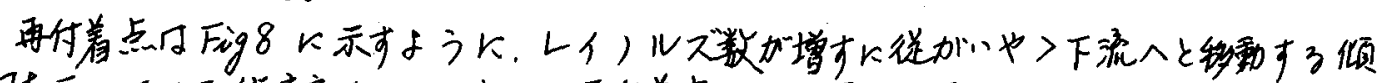

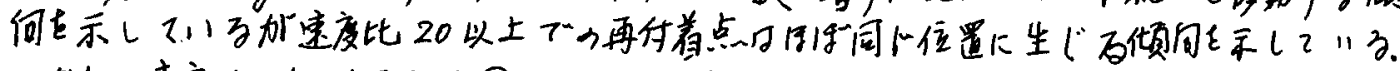
しかし，速度比15以下ではReが400以人上でけ下流へ上，Reが400以下でタ上流へ

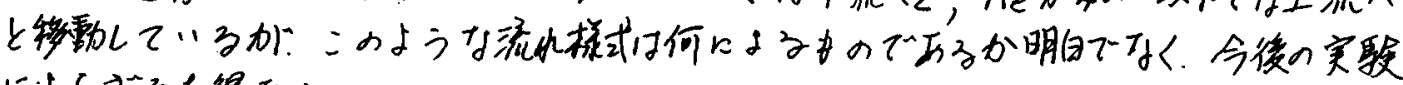
によらでろと得的。

5. 結言。

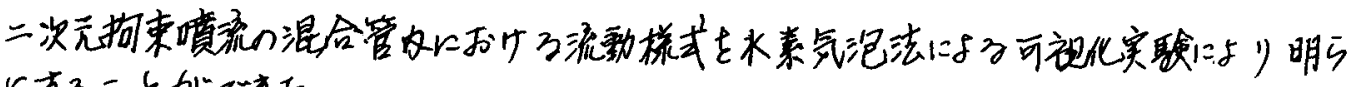
かにうることがでゔ。

文 献 (I) Curtet, R., Combustion and Flame, Vol.2, No.4, Dec. 1962.

(2) Curtet, R., and Barchilon, M., Trans. ASME, Serples D, Vol.86, No.4, Dec. 1964, 777.

(3) Exley, J. T., and Brighton, J. A., Trans. ASME, Serles D, Vol.93, June, 1971, 192. 